\title{
Age-related differences in decision-making process in the context of healthy aging
}

\author{
Felix Zakirov ${ }^{1,2^{*}}$, and Arsenty Krasilnikov ${ }^{3}$ \\ ${ }^{1}$ I. M. Sechenov First Moscow State Medical University (Sechenov University), 119991, Moscow, \\ Russian Federation \\ ${ }^{2}$ Institute of Higher Nervous Activity and Neurophysiology of RAS, 117485, Moscow, Russian \\ Federation \\ ${ }^{3}$ Moscow City University, Institute of Natural Sciences and Sports Technologies, 117303, Moscow, \\ Russian Federation
}

\begin{abstract}
During aging cognitive functions change differently from others. Unlike most of the body systems, there is no clear decline pattern in cognitive processes. One of the most significant cognitive processes is decision-making, which defines social interactions, economical relationships, and risky behavior. Among factors influence decisionmaking process, individual lifelong experience is considered to be an important one. Obviously, older adults have more life experience, than the younger groups. However, the former often do not tend to rational choices and beneficial strategies. In this case it is important to assess how aging processes in brain contribute into searching for the most beneficial option during decision-making. On the basis of today's studies about risky behavior, judgement of fairness, financial games, and modern neuroimaging data this review will observe and discuss age-related differences in decision-making. Thus, a correct cognitive profile of older adult in decision-making context can be determined.
\end{abstract}

\section{Introduction}

Aging is a complex process, which is common for every human being. During aging the most of physiological systems and body functions are getting less effective as well as less resistant to harmful environmental stimuli [1]. However, there is one function, which in some cases demonstrates even more impressive and successful results while getting older: cognition. Indeed, in the absence of diseases, human brain maintains proper functioning, which sometimes is even facilitated by collected lifelong experience. This life experience comprises all the individual's significant events, skill, and knowledge, thus making individual more adapted to certain environment [2-3]. The cognition involves many aspects of intellectual functions, such as attention, perception, reasoning, processing of memory, and decision-making [4]. The latter represents not only successful life tasks solving, but defines social interactions and behavior. Decision-making is considered to be a part of all economic relationships, risk evaluation, and of social cognition [5].

\footnotetext{
${ }^{*}$ Corresponding author: nilski@mail.ru
} 
The individual experience gained throughout life determines decision-making process, because it is based on the previous succeeds and rewards as well as on failures [6]. Thus, we may expect unequal behavior in risky and ambiguous situations in peoples of different age groups. Will the elder act more rationally all the time? Or does human brain tends to lose rationality with aging? Basically, the rational thinking is not simple to assess and, regarding to decision-making, neuroscientific studies associate it with ability to find the most beneficial option. During this search individual should evaluate possible risks, rewards, fairness, assess desirable and undesirable outcomes [7]. In this case, financial games, gambling tasks, and ethical questions are widely used to study decision-making process [8-10]. Modern studies also assess neurophysiological correlates of this process via neuroimaging techniques, such as functional magnetic resonance imaging (fMRI), electroencephalography (EEG), magnetoencephalography (MEG), positron emission tomography (PET), diffusion tensor imaging (DTI) [11].

In this review, we will address to age-related differences in decision-making and discuss possible explanations and neural correlates of these differences.

\section{Materials and Methods}

\subsection{Literature search}

The search was conducted in PubMed, Embase, PsychArticles, PsycINFO databases, using the following keywords: neurocognitive aging, healthy aging, decision-making, rational thinking, rational choice, reward-related behavior, financial decisions, ultimatum game, Iowa gambling task, lottery choice task, delay-discounting, evaluation of fairness, framing effect, risky behavior, decision outcomes, reward learning, outcome bias, cognitive bias, cognitive conflict, fMRI, EEG, MEG, neuroimaging, probability judgement, reasoning task, risk perception, risky choice, social behavior, lifelong experience.

The search was limited to articles published from 2010 to the present in order to keep the relevance of the current review. At the same time, since decision-making research is a relatively new field of neuroscience, the limit by year still provided a substantial amount of available studies.

\section{2 Inclusion criteria}

To be included into the consideration, studies were required to involve an assessment of age-dependent changes in decision-making process via original experimental study, or meta-analysis. All subjects recruited for the studies should not have any neurological or psychiatric diagnosis, thus representing healthy aging process. Subjects considered as older adults should have been at age of 65 or older. Decision tasks could include decision-making under uncertainty, multi-dimensional decision-making, preference-based decision making, and organized as real-life decisions or games. Appropriate statistics were required to be described (or to be available from the corresponding author) in the article for its inclusion.

\section{3 Exclusion criteria}

Animal studies and experimental studies, which did not observe older adult subjects were excluded. Clinical studies comprised patients, or subjects, who used psychotropic medications, were either excluded. Articles published in a language other than English were out of consideration. Non peer-reviewed literature was excluded. 


\section{Results and Discussion}

\section{1 Developmental factors}

Even in healthy aging there are neurocognitive changes, which occur in the most of individuals. They include declines in attention, memory, conceptual reasoning, and in other executive functions [12]. At the same time, some functions, for example, visuospatial perception, language processing remain intact [13]. Moreover, vocabulary may even improve with age, as well as individual lifelong experience, which is being constantly enriched and affects decision-making process greatly. Nevertheless, cognitive abilities obviously seem to decrease during aging process [14].

Addressing to neural basis of age-related neurocognitive changes, neuroimaging data may be considerable. There is a strong evidence that many functional and structural changes occur in brain when growing older [15]. One of the most obvious is progressive tissue volume loss, which affects white and grey matter [16]. In some degree the atrophy covers almost all brain regions, however, related to cognitive functions, frontal and temporal lobe volume loss appears to be the most crucial [17-20]. Generally, the atrophy is linked not only to neuronal death, but also to synaptic loss [21]. It can reflect cognitive declines, and decrease of memory function [22]. White matter tracts, which consist mainly of axons, were also reported to be influenced by aging process [23-24]. With DTI it was shown, that white matter tracts tend to lose integrity with increasing age, so that defining deficits in cognitive functions [25].

On the functional level, there is also descending pattern due to decrease of metabolic activity in neural cells [26]. The evidence of that comes from the fMRI data while measuring blood-oxygen-level-dependent (BOLD) signal - indicator of cell metabolism. It was shown, that BOLD signal in older subject is decreased, particularly in prefrontal cortex [27-28]. Thus, morpho-functional changes occur during healthy aging overall demonstrate pattern of decline. However, older adults do not indicate any serious restrictions or limitations in cognitive activities, so that examination of their decision-making strategies still remains reasonable.

\section{2 Risk-taking behavior}

Risky behavior can occur as a result of tolerance to high probability of unfavorable outcome (for example, money loss), and in this case brain mechanisms of risk evaluation can be declined [29]. At the same time, risk-taking can be demonstrated due to lower sensitivity to positive and negative outcomes (i. e. deficit in reward learning). In both conditions, diminished neural processing in certain brain regions can be observed [30-33].

Age-related differences in risky behavior were described in a number of studies, including financial games, as well as applied decision-making [34-36]. In the most of the studies risk-taking was reported to increase during aging, with elder adults being the most prone to risky decisions. In the mixed lottery task older adults tend to make choices according to the amount of possible reward, but not to probability of winning or losing [37]. In accordance with possible explanations mentioned above, dysfunction of neural mechanisms underlying goal-oriented behavior has been proposed. Altered reward learning in elder adults can be a result of decreased frontostriatal connectivity between ventral striatum (VS) and prefrontal cortex [38]. Moreover, in younger groups, VS is involved in possible outcome processing in higher degree, than in older adults. The latter demonstrated greater involvement of cortical areas, such as dorsolateral prefrontal cortex (DLPFC) and ventromedial prefrontal cortex (VMPFC) [39]. Thus, the basis of such behavior can be not only altered functioning, but also different activation pattern in the brain. 


\section{3 Fairness sensitivity and reciprocity}

The judgement of fairness is considered to be one of the key factors in social decisionmaking [40]. Among decision-making models, the ultimatum game (UG) is often used during examination of fairness preferences [41]. In the UG two players are required: the first one (proposer) offers to divide a sum of money in any proportion, the second one (responder) has to accept or reject the offer. In case of rejection, both players earn nothing. From the rational point of view, it is more beneficial to accept any offer, even unfair one [42]. However, usually people prefer to reject unfair offers (less than 20\%) in the UG [43].

It was shown, that evaluation of fairness significantly changes with aging process [44]. While small children tend to be fair and follow equal distributions, from the early adolescence and later this tendency shifts to inequity [45]. Compared to younger adults, elders demonstrate lower acceptance rate of unfair offers, with simultaneously higher expectations from the proposer in the UG [46]. Although following disadvantageous strategy, possible explanation can be found while analyzing overall scores after several trials of the UG. Some studies show the elder groups to have higher total payoff, than younger adults, making their strategy more beneficial [47-48]. In this case, rejection of unfair offers could lead to more generous distributions from the same proposers in subsequent trials (i. e. reciprocity). From the neural point, there is a difference in the intensity of brain regions activation during the $\mathrm{UG}$, although the patterns remain the same. FMRI data evidence higher activation in DLPFC and inferior parietal gyrus after processing of fair offers, and lower activation in anterior insula after unfair offers [49-50].

\section{4 Empathy and moral judgement}

Strategies, which older adults tend to follow during decision-making can be less rational not only because of light cognitive declines, but due to different sensitivity to some aspects of their choices. During interaction with other subjects, different values and goals can be predominant. In addition to that, there are certain priorities on the perceptual level, for example age-related positivity effect, which states that older adults pay more attention to positive stimuli, than to negative ones [51-53]. This effect can help with interpretation of their preferences in the mixed lottery task and in the Iowa gambling task [54-55].

Another point is that older subjects put a higher priority on social values, than on monetary rewards [56-57]. In this case, desirable result can include facilitated mutual interaction and reciprocity, but not the highest payoff. On the other hand, older adults were also shown to prioritize moral values, and to demonstrate more negative reactions to moral violations (for example, unfair money distribution) [58-60]. Thus, we may conclude, that positive affective component and social values become more prominent in the older adult decision-making process.

\section{Conclusion}

On the basis of today's reports about cognitive functions in older adults, we may conclude, that there is a specific cognitive profile in this age group. The differences in brain structure and its functional activity reflects particular patterns of goal-oriented and social behavior. Taken together, this defines certain strategies in decision-making which older adults tend to follow: risk-taking, reciprocity, high moral judgement. Thus, a cognitive profile of an older adult can be determined. These conclusions indicate future aims and scope for basic and applied research. 


\section{References}

1. R. Cabeza, M. Albert, S. Belleville, F.I.M. Craik, A. Duarte, C.L. Grady, U. Lindenberger, L. Nyberg, D.C. Park, P.A. Reuter-Lorenz, M.D. Rugg, J. Steffener, M.N. Rajah, Nat. Rev. Neurosci., 19, 701 (2018)

2. D.P. McGovern, A. Hayes, S.P. Kelly, R.G. O’Connell, Nat. Hum. Behav., 2, 955 (2018)

3. W.J. Phillips, J.M. Fletcher, A.D.G. Marks, D.W. Hine, Psychol. Bull., 142, 260 (2016)

4. C.N. Harada, M.C. Natelson Love, K. Triebel, Clin. Geriatr. Med., 29, 737 (2013)

5. K.M. Harlé, A.G. Sanfey, Neuropsychologia, 50, 1416 (2012)

6. N.J. Blanco, B.C. Love, M. Ramscar, A.R. Otto, K. Smayda, W.T. Maddox, J. Exp. Psychol. Gen., 145, 284 (2016)

7. J.K. Rilling, A.G. Sanfey, Annu Rev. Psychol., 62, 23 (2011)

8. R.P. Mann, Proc. Natl. Acad. Sci. U.S.A., 115, E10387 (2018)

9. S.W. Kennerley, M.E. Walton, Behav. Neurosci., 125, 297 (2011)

10. R. Ratcliff, Psychol. Rev., 125, 888 (2018)

11. T. Talukdar, F.J. Román, J.T. Operskalski, C.E. Zwilling, A.K. Barbey, Hum Brain Mapp, 39, 2664 (2018)

12. D.A. Camfield, L. Owen, A.B. Scholey, A. Pipingas, C. Stough, Br. J. Nutr., 106, 159 (2011)

13. S.L. Leal, M.A. Yassa, Trends Neurosci., 38, 800 (2015)

14. E.M. Tucker-Drob, Neuropsychology, 25, 368 (2011)

15. F.M. Nadal-Nicolás, M. Vidal-Sanz, M. Agudo-Barriuso, Aging (Albany NY), 11, 15 (2018)

16. D. Bano, M. Agostini, G. Melino, P. Nicotera, Mol. Neurobiol., 43, 124 (2011)

17. J.H. Morrison, M.G. Baxter, Nat. Rev. Neurosci., 13, 240 (2012)

18. R. Schliebs, T. Arendt, Behav. Brain Res., 221, 555 (2011)

19. J.Y. Hahr, Med. Hypotheses, 123, 83 (2019)

20. S.R.K. Hokkanen, S. Hunter, T.M. Polvikoski, H.A.D. Keage, T. Minett, F.E. Matthews, C. Brayne, and MRC CFAS and CC75C Study Group, Brain Pathol., 28, 548 (2018)

21. M. Henderson, B. Urbanc, L. Cruz, Biophys. J., 106, 2233 (2014)

22. K. Kim, H.K. Choe, Mech. Ageing Dev., 177, 74 (2019)

23. H. Chow, K. Herrup, Nat. Rev. Neurosci., 16, 672 (2015)

24. D.V. Telegina, G.K. Suvorov, O.S. Kozhevnikova, N.G. Kolosova, Int. J. Mol. Sci., 20, (2019)

25. C.J. Molloy, S. Nugent, A.L.W. Bokde, J. Gerontol. A Biol. Sci. Med. Sci. (2019)

26. J.S. Damoiseaux, Neuroimage, 160, 32 (2017)

27. S. Colangeli, M. Boccia, P. Verde, P. Guariglia, F. Bianchini, L. Piccardi, Am. J. Alzheimers Dis. Other Demen., 31, 443 (2016)

28. L. Nyberg, J. Intern. Med., 281, 65 (2017)

29. E. Di Rosa, D. Mapelli, G. Arcara, P. Amodio, S. Tamburin, S. Schiff, Neurosci. Lett., 640, 93 (2017)

30. Z. Kardos, A. Kóbor, Á. Takács, B. Tóth, R. Boha, B. File, M. Molnár, Behav. Brain Res., 312, 405 (2016)

31. R. Frey, R. Mata, R. Hertwig, Cognition, 142, 60 (2015)

32. M.A. Grubb, A. Tymula, S. Gilaie-Dotan, P.W. Glimcher, I. Levy, Nat. Commun., 7, $13822(2016)$

33. B. Almy, M. Kuskowski, S.M. Malone, E. Myers, M. Luciana, Dev. Psychol., 54, 689 (2018) 
34. J. Schiebener, M. Brand, Cogn. Emot., 31, 816 (2017)

35. R.A. Cowell, E.R. Paitel, S. Peters, Int. J. Aging Hum. Dev., 90, 84 (2020)

36. M.-T. Pertl, T. Benke, L. Zamarian, M. Delazer, J. Alzheimers Dis., 58, 1077 (2017)

37. Y.-S. Su, J.-T. Chen, Y.-J. Tang, S.-Y. Yuan, A.C. McCarrey, J.O.S. Goh, Neurobiol. Aging, 69, 185 (2018)

38. G.R. Samanez-Larkin, S.M. Levens, L.M. Perry, R.F. Dougherty, B. Knutson, J. Neurosci., 32, 5333 (2012)

39. Z.A. Yaple, W.D. Stevens, M. Arsalidou, Neuroimage, 196, 16 (2019)

40. A. Girardi, S.D. Sala, S.E. MacPherson, Exp. Aging Res., 44, 246 (2018)

41. S.K. Horat, A. Prévot, J. Richiardi, F.R. Herrmann, G. Favre, M.C.G. Merlo, P. Missonnier, Front. Integr. Neurosci., 11, 13 (2017)

42. A.S. Gabay, J. Radua, M.J. Kempton, M.A. Mehta, Neurosci. Biobehav. Rev., 47, 549 (2014)

43. H. Zheng, L. Zhu, Neural Regen. Res., 8, 357 (2013)

44. Y. Hashimoto, Y. Toda, Early Child Development and Care, 189, 1051 (2019)

45. A. Marchetti, F. Baglio, I. Castelli, L. Griffanti, R. Nemni, F. Rossetto, A. Valle, M. Zanette, D. Massaro, Psychol. Rep., 122, 135 (2019)

46. D.R. Roalf, S.H. Mitchell, W.T. Harbaugh, J.S. Janowsky, The Journals of Gerontology: Series B, 67B, 289 (2012)

47. J.N. Beadle, S. Paradiso, C. Kovach, L. Polgreen, N.L. Denburg, D. Tranel, International Psychogeriatrics, 24, 822 (2012)

48. M. Inaba, Jpn. Psychol. Res., 57, 91 (2015)

49. M.A.S. Boksem, D.D. Cremer, Social Neuroscience, 5, 118 (2010)

50. N.R. Lighthall, S.A. Huettel, R. Cabeza, J. Neurosci., 34, 15648 (2014)

51. P.E. Bailey, C.J. Gonsalvez, M. Maiuolo, T. Leon, G. Benedek, Exp. Aging Res., 44, 135 (2018)

52. M.E. Roberts, E. Peters, A.K. Ferketich, E.G. Klein, Tob. Regul. Sci., 2, 176 (2016)

53. J.J. Rolison, Dev. Psychol., 55, 1788 (2019)

54. R. Kumar, K. Janakiprasad Kumar, V. Benegal, Asian J. Psychiatr., 39, 63 (2019)

55. J.O.S. Goh, Y.-S. Su, Y.-J. Tang, A.C. McCarrey, A. Tereshchenko, W. Elkins, S.M. Resnick, J. Neurosci., 36, 12498 (2016)

56. T. Kollmann, C. Stöckmann, J.M. Kensbock, A. Peschl, Human Resource Management 59, $101(2020)$

57. C. Fernandes, A.R. Gonçalves, R. Pasion, F. Ferreira-Santos, F. Barbosa, I.P. Martins, J. Marques-Teixeira, Neurosci. Lett., 692, 122 (2019)

58. S.C.S. Caravita, L.N. De Silva, V. Pagani, B. Colombo, A. Antonietti, Front. Psychol., 8 (2017)

59. S. McNair, Y. Okan, C. Hadjichristidis, W.B. de Bruin, J. Behav. Dec. Making, 32, 47 (2019)

60. D. Narvaez, G.A. Radvansky, N.A. Lynchard, D.E. Copeland, Exp. Aging Res., 37, 398 (2011) 